\title{
Meiotic analysis and FISH with rDNA and rice BAC probes of the Thai KPS 01-01-25 sugarcane cultivar
}

\author{
Sarut Thumjamras ${ }^{1,2} \cdot$ Siriluck Iamtham ${ }^{1,2,3} \cdot$ Siripatr Prammanee ${ }^{1,2,4} \cdot$ \\ Hans de Jong ${ }^{5}$
}

Received: 2 July 2015/Accepted: 11 November 2015/Published online: 9 December 2015

(c) The Author(s) 2015. This article is published with open access at Springerlink.com

\begin{abstract}
The interspecific sugarcane hybrid "KPS 01-01-25" is one of Thailand's most successful cultivars, but its genetics and genomic constitution are greatly complicated due to the highly polyploid nature of this crop. Here we analyzed the crop's karyotype, studied chromosome pairing at meiosis I and performed fluorescent in situ hybridization (FISH) of rDNA and rice BACs as probes. Mitotic cell complements in early tapetal cells showed 110 well-spread chromosomes. Pollen mother cells at pachytene clearly demonstrated fully paired configurations of the long chromosomes, in which few pairing partner exchanges and loops could be discerned. In diakinesis cells we observed $74.1 \%$ bivalents, $18.6 \%$ univalents, $2.9 \%$ trivalents and $4.4 \%$ quadrivalents. During this stage secondary associations were abundant, but these threadlike structures disappear after metaphase I. FISH with 5S rDNA produced up to ten fluorescent spots, of which 2-5 are often
\end{abstract}

Handling Editor: Martin Lysak.

Hans de Jong

hans.dejong@wur.nl

1 Institute for Advanced Studies, Center for Advanced Studies in Tropical Natural Resources, Kasetsart University,

Bangkok, Thailand

2 Department of Science, Faculty of Liberal Arts and Science, Program of Bioproduct Sciences, Kasetsart University, Kamphaeng Saen Campus, Kamphaeng Saen, Nakhon Pathom 73140, Thailand

3 Laboratory of Genetics, Kasetsart University, Kamphaeng Sean Campus, Kamphaeng Saen, Thailand

4 Laboratory of Biology, Kasetsart University, Kamphaeng Sean Campus, Kamphaeng Saen, Thailand

5 Laboratory of Genetics, Plant Science Group, Wageningen University, Wageningen, The Netherlands very small, whereas the $45 \mathrm{~S}$ rDNA probe showed foci on 8-9 chromosomes. Based on our results and that of related studies we estimate that this sugarcane is composed of 11-12 genomes. We also selected rice BACs containing chromosome 5 genes controlling economically important genes. Eight BACs with relatively strong dot-blot hybridization on genomic sugarcane DNA were selected for FISH on sugarcane chromosome slides. These crossspecies chromosome BAC FISH revealed weak signals, and most of the foci were distributed over parts of the chromosomes. Based on these experiments we concluded that cross-species FISH in sugarcane can better be carried out with sorghum BACs as probes.

Keywords Cross-species chromosome painting . Meiosis · rDNA FISH · Saccharum - Sugarcane

\begin{tabular}{|c|c|}
\hline \multicolumn{2}{|c|}{ Abbreviations } \\
\hline $4 \mathrm{~T}$ & 4XSSC and Tween-20 \\
\hline BAC & Bacterial artificial chromosome \\
\hline $\mathrm{C}_{0} t 100$ & $\begin{array}{l}\text { DNA enriched of repetitive sequences (the } \\
\text { initial concentration of DNA/s) }\end{array}$ \\
\hline Сy & Cyanine \\
\hline DAPI & 4',6-Diamidino-2-phenylindole \\
\hline DEAC & 7-Diethylaminocoumarin-3-carboxylic acid \\
\hline DIG & Digoxigenin \\
\hline FISH & Fluorescent in situ hybridization \\
\hline FITC & Fluorescein isothiocyanate \\
\hline HB50 & $\begin{array}{l}\text { Hybridization buffer with } 50 \% \text { deionized } \\
\text { formamide }\end{array}$ \\
\hline NBT/BCIP & $\begin{array}{l}\text { Nitroblue tetrazolium/5-bromo-4-chloro-3- } \\
\text { indolyl phosphate }\end{array}$ \\
\hline NOR & Nucleolar organizer region \\
\hline PBS & Phosphate buffered saline \\
\hline $\mathrm{SSC}$ & Saline-sodium citrate buffer \\
\hline
\end{tabular}


TE

TNT

TRIS-EDTA buffer

Wash buffer (Tris- $\mathrm{HCl} \mathrm{pH} 7.5, \mathrm{NaCl}$ and

Tween-20)

\section{Introduction}

Sugarcane (Saccharum spec.) is one of Thailand's most important crops. Its very high sucrose content is economically most profitable as food supplement and for biofuel production. Thailand is also a major producer of sugarcane worldwide and is as such the fourth largest in the world (http://faostat.fao.org). Saccharum officinarum is mostly known for the sweet, juicy stalk with soft rinds, whereas the wild related Chinese cane ( $S$. sinese), Indian cane ( $S$. barberi), New Guinea cane (S. robustum) and S. spontaneum species are potential introgression donors for disease resistance and abiotic tolerance (Roach 1972). Cytogenetic studies of sugarcane and related species revealed that the basic chromosome number for $S$. spontaneum is $x=8$, whereas $S$. officinarum and $S$. robustum have $x=10$ (Ha et al. 1999; Piperidis and D'Hont 2001; D'Hont 2005). Total genome sizes of modern cultivars are about $10 \mathrm{~Gb}$ and can contain up to 130 chromosomes, of which $80-90 \%$ of the chromosomes originate from $S$. officinarum, 10-20\% from $S$. spontaneum and the rest from interspecific recombinations (D'Hont et al. 1996; D'Hont and Glaszmann 2001; Piperidis and D'Hont 2001; Cuadrado et al. 2004). Detailed knowledge on the complex polyploid genome compositions of these hybrids requires extensive genetic, genomic and cytogenetic studies.

Various molecular cytogenetic technologies have been developed for studying genomic composition of complex polyploid and hybrid genomes like wheat (Cuadrado and Jouve 1995; Vega et al. 1994), tomato (+) potato, banana and sugarcane (Jacobsen et al. 1995; D'Hont et al. 2000; D'Hont 2005). Fluorescent in situ hybridization (FISH), nowadays the most powerful and versatile cytogenetic tool, enables distinction of parental genomes in interspecific hybrids (D'Hont et al. 2000; Piperidis and D'Hont 2001; Figueroa and Bass 2010), as well as detection of single copy and repetitive DNA sequences and elucidates chromosomal rearrangements and aberrant chromosome behavior in mitotic and meiotic divisions (Fransz et al. 1996; Lim et al. 2001; Hodkinson et al. 2002). For chromosome identification and karyotype analyses FISH with the $5 \mathrm{~S}$ and $45 \mathrm{~S}$ rDNA probes was used on metaphase and pachytene complements and, where possible, was supplemented with FISH using species-specific repeats. Such information is most useful for comparing chromosome sets between related (polyploid) species (Jenkin et al. 1995; D'Hont et al. 1998; Cuadrado et al. 2004). FISH technology also allows detection of single and low copy sequences on the chromosomes. To this end genomic DNA of Arabidopsis (Wang et al. 1996), sorghum (Woo et al. 1994) and rice (Wang et al. 1995; Chen et al. 2002) in BACs (bacterial artificial chromosome) or in smaller insert vectors are used in FISH to map single copy sequences on the chromosomes, a technology that provide powerful tools for chromosome mapping, synteny studies and comparative genomics (Kim et al. 2002, 2013; Figueira et al. 2012).

In this study we aim at the cytogenetic characterization of Thai sugarcane cultivar "KPS 01-01-25". This variety has been chosen for its superior agronomical features including salt and drought tolerant, disease resistant and sufficient sugar capacity. Complementary to establishing its chromosome number, we also analyzed meiotic chromosome associations of this highly polyploid crop. We further performed FISH with the ubiquitous $5 \mathrm{~S}$ and $45 \mathrm{~S}$ rDNA repeats in order to determine ploidy level of this cultivar. Cross-species chromosome painting is used with rice chromosome 5 BACs that are known to contain economically important genes for grain width (Wan et al. 2008), root trait (Khowaja et al. 2009) and grain weight (Yoshida et al. 2002). The rice probes were then hybridized on spread sugarcane chromosome slides under adapted stringency conditions. We observed only few examples of single discrete fluorescent foci that may represent homeologous regions, but most signals are weak and spread along (parts) of the chromosomes. This study, which was setup as a first step in genetic and genome research of this highly polyploid crop, has potential for more advanced cytogenetic studies with other related BAC libraries for cross-species chromosome painting.

\section{Materials and methods}

\section{Chromosome preparation}

The Thai sugarcane (Saccharum spec.) cultivar "KPS 01-01-25", developed by the Cane and Sugar Research and Development Center of Kasetsart University and obtained from a KPS 94-13 $\times$ UT3 cross, was used in our experiments. We collected young flower buds with 1-2 mm anthers containing pollen mother cells at meiosis between 9 and $10 \mathrm{am}$, and fixed the material directly in freshly prepared ethanol $96 \%$-acetic acid $(3: 1 \mathrm{v} / \mathrm{v})$ for at least $1 \mathrm{~h}$. Subsequently, the flower buds were transferred to ethanol $70 \%$, in which it could be stored for up to several months at $4{ }^{\circ} \mathrm{C}$ until further treatment. We also collected fast growing rootlets of Japanese rice (Oryza sativa subsp. japonica var. Nipponbare) for control experiments testing the rice BACs (see below). The rice roots were collected in the early morning and were pretreated with $2 \mathrm{mM} 8$-hydroxyquinoline for $4-6 \mathrm{~h}$, followed by fixation in $70 \%$ 
ethanol and kept in the fridge until further use. On the day of slide making we washed the material three times in Milli-Q and then two times in $10 \mathrm{mM} \mathrm{Na}$-citrate buffer ( $\mathrm{pH}$ $4.5)$ for $3 \mathrm{~min}$. The flower buds and root tips were carefully dissected under the binocular and transferred to an enzyme solution containing $1 \%$ cellulase RS (Yakult 203027), $1 \%$ pectolylase Y23 (Sigma P-3026) and $1 \%$ cytohelicase (Bio Sepra 249701) for $1-2 \mathrm{~h}$ at $37^{\circ} \mathrm{C}$. A piece of the very soft and fragile tissue was put to a clean slide and dissected in a tiny bit of water with fine needles. The loose cells were then macerated by adding a drop of 45-50\% acetic acid to cover an area of c. $24 \times 24 \mathrm{~mm}$ and this was kept on a $50{ }^{\circ} \mathrm{C}$ hotplate for $2 \mathrm{~min}$. The slides were rinsed again in freshly prepared ethanol $96 \%$ :glacial acetic acid (3:1) and finally air-dried. We selected only the best slides containing well-spread cells and clear chromosomes that were not covered by cytoplasm.

\section{DNA isolation and probe labeling}

The plasmid clones, pTa794 (Gerlach and Dyer 1980) and pTa71 (Gerlach and Bedbrook 1979), which contain 5S and $45 \mathrm{~S}$ rDNA genes, respectively, were cultured in $3 \mathrm{~mL} \mathrm{LB}$ broth (BD Difco ${ }^{\mathrm{TM}}$, Miller; Luria-Bertani broth) with $12.5 \mu \mathrm{g} / \mathrm{mL}$ chloramphenicol (NZYTech) in a $25 \mathrm{~mL}$ centrifuge tube. The tubes were then shaken overnight at 225-300 rpm at $37^{\circ} \mathrm{C}$. Next day the cultures were spun down at $6000 \mathrm{~g}$ for $15 \mathrm{~min}$ and $4{ }^{\circ} \mathrm{C}$, supernatants discarded and plasmids isolated with the QIAGEN Plasmid Midi Kit. Before using the plasmids for labeling, we checked the sequence target with 7-10 $\mathrm{LL} \mathrm{BamH1}$ (Promega) or Hin$d$ III (Promega) restriction enzymes. The 5S rDNA was labeled with biotin using the protocol of Biotin Nick Translation Mix (Roche) and detected with streptavidinCy3.5 (Amersham/Phamacia); the 45S rDNA was directly labeled with DEAC (Invitrogen, http://www.life technologies.com) using the Nick Translation Mix (Roche).

We also selected twenty chromosome-5 BACs from the OSJNBa BAC Library of Oryza sativa subsp. japonica var. Nipponbare (CUGI, Clemson University Genomics Institute, USA, http://www.genome.clemson.edu), see also: The International Rice Genome Sequencing Project, IRGSP (reviewed by Sasaki and Burr 2000; Cheng et al. 2005). BACs with genetic markers near the genes for grain width (Wan et al. 2008), grain weight of rice (Yoshida et al. 2002), and root trait (Khowaja et al. 2009) were chosen (Table 1). The E. coli strains containing the selected rice BACs were transferred to $1 \mathrm{~mL} \mathrm{LB}$ medium with $12.5 \mu \mathrm{g} /$ $\mathrm{mL}$ chloramphenicol and spread on a LB agar plate with $10 \mu \mathrm{L} \mathrm{LB}$, and were left to grow overnight at $37{ }^{\circ} \mathrm{C}$. Single BAC colonies were inoculated in $3 \mathrm{~mL} \mathrm{LB}$ with $12.5 \mu \mathrm{g} /$ $\mathrm{mL}$ chloramphenicol in a $25 \mathrm{~mL}$ centrifuge tube and shaken overnight at $225-300 \mathrm{rpm}$ and $37^{\circ} \mathrm{C}$. We added $1 \mathrm{~mL}$ of last cultured $E$. coli into $100 \mathrm{~mL} \mathrm{LB}$ with $12.5 \mu \mathrm{g} / \mathrm{mL}$ chloramphenicol in a $250 \mathrm{~mL}$ Erlenmeyer flask, while shaking at $225-300 \mathrm{rpm}, 37^{\circ} \mathrm{C}$. The cultured strains were harvested and its DNA isolated using the QIAGEN Plasmid midi kit. The rice BAC sequences were labeled with the Biotin Nick Translation Mix (Roche) and amplified with streptavidin conjugated with Cy3, Cy3.5 or Cy5 (Amersham/Pharmacia), or labelled with digoxigenin using the DIG Nick Translation Mix (Roche), followed by detection with anti-dig FITC (Roche).

We also tested the selected BACs by DNA dot-blot hybridization on sugarcane DNA with DIG Easy Hyb Granules (Roche). The digoxigenin (DIG)-labeled sugarcane genomic DNA was hybridized onto target bound sugarcane template DNA in a dilution series as control and the 20 rice BACs DNA in a dilution of $1 \mu \mathrm{g}, 100,10,1 \mathrm{ng}$, 100 , and $10 \mathrm{pg}$, respectively, on nylon membrane (Roti ${ }^{\circledR}$ Nylon plus). The membrane was incubated at $50-60{ }^{\circ} \mathrm{C}$ with NBT/BCIP (Promega). After hybridization the NBT/ BCIP was washed off with preheated dimethylformamide (Armar) and double distilled water before air-drying.

For suppressing hybridization of repetitive probe DNA on the chromosomes we used $\mathrm{C}_{0} t 100$ genomic DNA as non-specific repeat blocker in the FISH following the standard protocol of Zwick et al. (1997). Genomic DNA was diluted to $100-500 \mathrm{ng} / \mu \mathrm{L}$ in $0.3 \mathrm{M} \mathrm{NaCl}$ and then was sheared with the Q55 sonicator (http://www.sonicator.com) at $50 \%$ amplitude for $15 \mathrm{~min}$ at $4{ }^{\circ} \mathrm{C}$, and alternatively switched on and off for $50 \mathrm{~s}$. each. In this way we obtained DNA fragments of 100-1000 bp. DNA was denatured at $95{ }^{\circ} \mathrm{C}$ for $10 \mathrm{~min}$ and then cooled down in ice water for 10 s. Denatured DNA was reannealed at $65^{\circ} \mathrm{C}$ for $47 \mathrm{~h}$ (Zwick et al. 1997), after which single-stranded DNA was digested with $1 \mathrm{U} / \mu \mathrm{g}$ of DNA S1 nuclease (Cat No. 818 348 , Roche) at $37^{\circ} \mathrm{C}$ for $90 \mathrm{~min}$. The DNA was then precipitated two times with equal volume of phenol-chloroform and chloroform-isoamylalcohol (24:1), and then precipitated overnight with 2.5 volume of absolute ethanol at $-20{ }^{\circ} \mathrm{C}$. The solution was spun-down for $30 \mathrm{~min}$ at $11,000 \mathrm{rpm}$ at $4{ }^{\circ} \mathrm{C}$. The DNA pellet was re-suspended in 10-20 $\mu \mathrm{L}$ TE buffer ( $\mathrm{pH} 7.0$ ). The $\mathrm{C}_{0} t 100$ was quantified with a UV-spectrometer, and stored at $-20{ }^{\circ} \mathrm{C}$, until use.

\section{Fluorescent in situ hybridization}

Selected slides were incubated in $100 \mu \mathrm{g} / \mathrm{mL}$ RNase-A in 2XSSC for $1 \mathrm{~h}$ at $37{ }^{\circ} \mathrm{C}$, washed three times in 2XSSC for $5 \mathrm{~min}$ and fixed in freshly prepared $1 \%$ formaldehyde buffer in PBS with $50 \mathrm{~mL} \mathrm{MgCl}_{2}$, washed again three times in 2XSSC, dehydrated through an ethanol series $(70$, 90 and $96 \%$ ethanol) for 3 min each, and finally air-dried for at least $30 \mathrm{~min}$. We used $20 \mathrm{~mL}$ hybridization mix per slide (10\% dextran sulfate, HB50, 0.25-0.5\% salmon 
Table 1 Selected BAC clones locate near/on the drought genes of chromosome 5 of Japanese rice, Oryza sativa subsp. japonica var. "Nipponbare"

\begin{tabular}{|c|c|c|c|c|c|}
\hline BAC clone & Position on rice chr5 $(\mathrm{cM})$ & 5p: short arm; 5q: long arm & Marker & Accession & Length (bp) \\
\hline OSJNBa0077J22 & $22.5-24.7$ & $5 p$ & - & $\mathrm{AC} 148814$ & 173,903 \\
\hline OSJNBa0072C16 & 25.0 & $5 p$ & E30256S & AC093493 & 159,525 \\
\hline OSJNBa0059G01 & $25.0-27.7$ & $5 p$ & - & AC093492 & 141,661 \\
\hline OSJNBa0017J22 & 29.1 & $5 \mathrm{p}$ & S12447 & AC119288 & 177,153 \\
\hline OSJNBa0027N19 & $30.7-31.5$ & $5 p$ & - & AC134341 & 141,368 \\
\hline OSJNBa0029B02 & 33.6 & $5 p$ & S16612S & AC144738 & 156,649 \\
\hline OSJNBa0015G13 & $42.2-44.7$ & $5 p$ & - & AC135920 & 143,966 \\
\hline OSJNBa0074P11 & 45.8 & $5 p$ & S12928 & AC135914 & 148,753 \\
\hline OSJNBa0042F15 & 51.3 & $5 p$ & E3093S & AC145396 & 162,959 \\
\hline OSJNBa0052E20 & 96.1 & $5 q$ & C536 & AC121364 & 162,434 \\
\hline OSJNBa0018K15 & 98.3 & $5 q$ & C10405S & AC144737 & 168,519 \\
\hline OSJNBa0095J22 & $98.3-101.0$ & $5 q$ & - & AC137619 & 151,730 \\
\hline OSJNBa0088I06 & $101.5-102.8$ & $5 q$ & - & AC129718 & 187,651 \\
\hline OSJNBa0017K09 & 103.1 & $5 q$ & R38028 & AC130597 & 155,525 \\
\hline OSJNBa0052K01 & $108.5-109.0$ & $5 q$ & - & AC119291 & 144,395 \\
\hline OSJNBa0079H23 & 111.6 & $5 q$ & C686 & AC129717 & 191,765 \\
\hline OSJNBa0001A14 & $112.4-115.7$ & $5 q$ & - & AC144735 & 129,292 \\
\hline OSJNBa0017N18 & 117.9 & $5 q$ & C444 & AC120988 & 156,643 \\
\hline OSJNBa0009C07 & 120.6 & $5 q$ & S11036 & AC137608 & 148,731 \\
\hline OSJNBa0030I14 & 122.3 & $5 q$ & - & AC136217 & 159,035 \\
\hline
\end{tabular}

sperm DNA or $20 \mu \mathrm{L} /$ slide sugarcane $\left.\mathrm{C}_{0} t 100\right)$ and covered it with a $24 \times 50 \mathrm{~mm}$ cover slip. Chromosomes were denatured at $100{ }^{\circ} \mathrm{C}$ for $10 \mathrm{~min}$, after which the slides were put on ice for at least $5 \mathrm{~min}$. We then heated the slides for another $3 \mathrm{~min}$ at $80^{\circ} \mathrm{C}$ and placed them in a humidified petri dish at $37{ }^{\circ} \mathrm{C}$ for incubation overnight. The post-hybridization washing step consisted of three times washing the slides in 2XSSC for $5 \mathrm{~min}$ and three times in $50 \%$ formamide/0.1XSSC at $42{ }^{\circ} \mathrm{C}$. For cross-species FISH we adapted the post-hybridization washing to $20 \%$ formamide in $0.1 \mathrm{XSSC}$ for $3-5 \mathrm{~min}$ at $42^{\circ} \mathrm{C}$. Probe DNA was detected/amplified with biotin-anti-streptavidin and biotinstreptavidin-Alexa 647 (Invitrogen, Life Sciences), or with sheep-anti-DIG-FITC and rabbit-anti-sheep-FITC (SigmaAldrich) for $1 \mathrm{~h}$ at $37^{\circ} \mathrm{C}$ of each. In few experiments we used the fluorescence systems with DEAC and Cy5. The slides were washed with 4T, TNT and 2XSSC for $5 \mathrm{~min}$ of each, respectively, and dehydrated through an ethanol series before air-drying. The chromosomes were counterstained with $12 \mu \mathrm{L}$ DAPI in $50 \mu \mathrm{L} / \mathrm{mL}$ Vectashield antifade solution (https://www.vectorlabs.com/). The selected meiotic prophase I slides were studied under a Zeiss Axioplan microscope equipped with Plan Apochromatic objectives and epifluorescence illumination with filters for all used fluorophores. Images were captured with the Photometrics Sensys monochrome $1305 \times 1024$-pixel CCD camera and processed with Genus Image Analysis
Workstation software (http://www.well.ox.ac.uk/). For each cell we combined the different fluorescence captures in a multichannel mode image while setting threshold values for each of them to optimize best contrast and brightness. If needed, we further improved the quality of the images with Adobe Photoshop.

\section{Results}

\section{Chromosome number and morphology}

For counting the number of chromosomes in this highly polyploid plant we used cell spreading slides obtained from young anthers containing pollen mother cells at premeiotic interphase to early prophase I and diploid tapetal cells. Chromosome complements in tapetal cells are highly condensed and better spread than the chromosomes in mitotic metaphase cells in fast growing root tip meristems. Accordingly, diploid tapetal nuclei in very young anthers from the KPS sugarcane variety contain cell complements of 110 highly condensed chromosomes varying in length from 1.25 to $1.9 \mu \mathrm{m}$ (Fig. 1a). In anthers containing pollen mother cells at pachytene chromosomes are long and well differentiated with numerous smaller chromomeres and fewer brightly fluorescing peri centromere regions forming big chromatin clusters. However, chromosomes could in 
general not be traced completely (Fig. 1b). Long stretches of triple or quadruple pairing could not be detected with certainty, but several examples of pairing partner switches and inversion/deletion loops were observed (Fig. 1b, details in the three insets). However, we were not able to follow such long chromosomes from end to end. Pollen mother cells at diakinesis displayed complex networks of bivalents and univalents/multivalents (Table 2). Most of these chiasma associations and univalents are interconnected by thin up to $7.0 \mu \mathrm{m}$ long chromatin threads. Such interconnections, which may comprise up to 12 chromosomes (bivalents and univalents) (Fig. 1c) are known as secondary chromosome associations (Lawrence 1931) and result from the loose association of bivalents without the existence of chiasmata. Table 3 summarizes the number of such associations in 16 nuclei obtained from seven slides. The number of chromosomes involved in such complexes varied in number and appearances between anthers that were sampled on different days. At the end of the meiotic congression at (pro)metaphase I, when chiasmata orient to
Fig. 1 Mitotic and meiotic stages in young anthers of the sugarcane cultivar "KPS 01-0125 ". Chromosomes in all figures were stained with DAPI. a A full cell complement in a diploid tapetum cell showing 110 chromosomes. b Pollen mother cell at pachytene. The three insets show details of the morphology. Arrows indicate pairing partner switches and knobs; the arrowhead points at a small loop. c Pollen mother cell at diakinesis. The bivalents and few univalents are well spread, but are connected by fine chromatin threads, so-called secondary associations. The detail image (right) shows a higher magnification of such a network involving 10 or 11 bivalents. d Pollen mother cell at prometaphase I. The cell has mostly bivalents (middle inset), few univalents (bottom inset). Some of the bigger associations may represent multivalents (top inset). e Cell complement at anaphase I. The arrowhead shows a chromosome-bridge, whereas the arrow points at lagging chromosomes, bar $5 \mu \mathrm{m}$

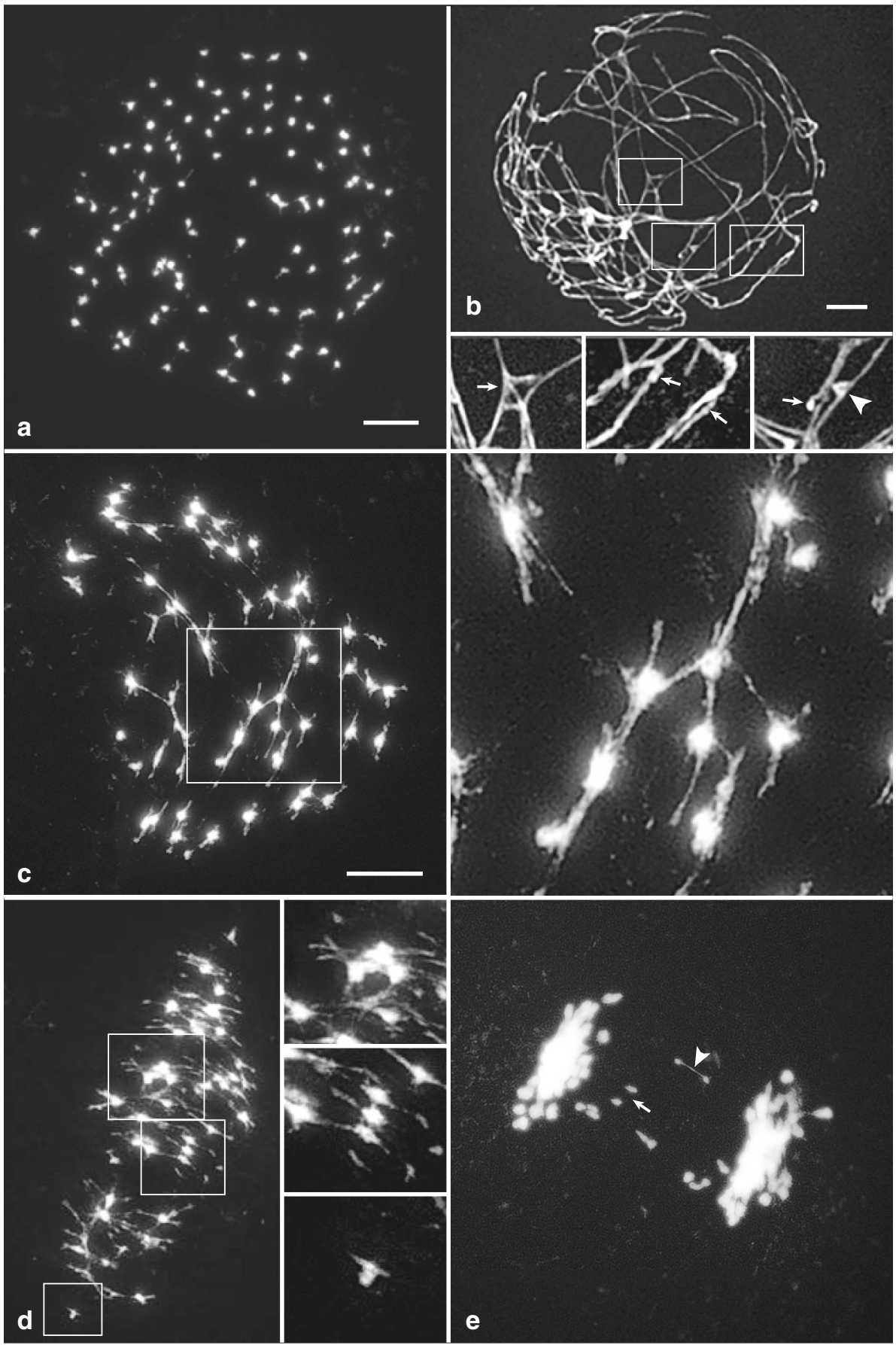


Table 2 Chiasma configurations in 16 pollen mother cells at diakinesis of the KPS 01-01-25 sugarcane (univ univalents, biv bivalents, triv trivalents, qua quadrivalents)

\begin{tabular}{lllllr}
\hline & \multicolumn{5}{c}{ Chiasma configurations } \\
\cline { 2 - 5 } & Univ & Biv & Triv & Qua & Total \\
\hline Total number & 170 & 676 & 26 & 40 & 912 \\
Total number of chromosomes & 170 & 1352 & 78 & 160 & 1760 \\
Percentage configurations & 18.6 & 74.1 & 2.9 & 4.4 & 100 \\
\hline
\end{tabular}

the equational plane and centromere facing their opposite poles, we observed that the majority of chiasma associations where that of bivalents, whereas few univalents could be discerned as well (Fig. 1d, and details in magnified insets). At anaphase I we observed very few chromosome bridges, precocious chromatid segregations and lagging chromosomes (Fig. 1e).

\section{FISH detection of rDNA regions}

Based on the assumption that a basic (monoploid) sugarcane genome contains one chromosome with 5S rDNA and one with 45S rDNA in the cell complement (D'Hont et al. 1998), we used rDNA FISH of the KPS 01-01-25 as an estimate of the ploidy level of the cultivar. The FISH experiments with the $5 \mathrm{~S}$ rDNA probe showed 5 big and up to five smaller foci in metaphase chromosome sets (Fig. 2a, b). Some of the foci are composed of few smaller signals. In interphase nuclei we generally see brighter fluorescent spots (data not shown), varying in number from 10 to 15 foci. Hybridization with the 45S rDNA probe on metaphase and interphase cells showed only 8 , sometimes nine foci of this probe; in pachytene complements only one big fluorescing spot was observed at the border of the nucleolus (data not shown).

\section{Rice BAC FISH on rice and sugarcane chromosomes}

For the cross-species FISH we selected BACs from rice chromosome 5 as probes for FISH on slides containing spread anther cells. Figure $3 \mathrm{a}$ shows the 20 rice BACs, which include nine BACs for rice chromosome arms $5 p$ and 11 BACs for chromosome arm 5q. Table 1 describes the BACs covering the chromosome regions around drought genes for grain width $(a)$, root trait $(b)$ and grain weight $(c)$. Further selection of the BACs was based on dot-blot hybridizations of these BACs on genomic sugarcane DNA, which showed relatively strong hybridization signals for the rice BACs 77J22, 72C16, 17J22, 29B02, 52E20, 95J22, 52K01 and 79H23 (Fig. 3b). We decided to continue with only these BACs in the cross-species BAC FISH experiments. The two pools of BACs were labeled and detected with digoxigenin-FITC and biotin-Cy 3.5 and $\mathrm{Cy} 5$, respectively, and hybridized these with the $45 \mathrm{~S}$ rDNA directly labeled with Cy5 in a FISH experiment on root tip cell spread slides of japonica rice demonstrating the expected clear foci on the two arms of the chromosome 5 and the NOR chromosome homologues (Fig. 3c).

Cross-species FISH of rice DNA on sugarcane chromosomes under $50 \%$ standard stringency produced only very weak fluorescent signals on the sugarcane chromosomes (data not shown). We therefore adapted stringency in the post-hybridization wash step to $20 \%$ to compensate for decreased homology between the rice and sugarcane DNA. In the Fig. $4 \mathrm{a}-\mathrm{h}$ we show examples of such crossspecies FISH using probes of the rice BACs, along with 45S rDNA painting on different diakinesis complements. To decrease fluorescencing repeat probe sequences from hybridization we added $\mathrm{C}_{0} t 100$ unlabeled genomic sugarcane DNA to block hybridization of repetitive DNA sequences, but also here were the resulting fluorescence signals weak (data not shown). The four BACs on the short arm of chromosome 5, 77J22, 72C16, 17J22 and 29B02 that were probed with the FITC system are presented on the Fig. 4a, c, e and g, respectively; those of the long arm, 52E20, 95J22, 52K01 and 79H23 were probed with biotin and detected with the indirect streptavidin $\mathrm{Cy} 5$ fluorescence system (Fig. 4b, d, f, h). The FISH of BAC 77J22 paints about half of the chromosomes (Fig. 4a), of which several chromosomes demonstrate clear fluorescent foci and some with weaker signals, of which few show small discrete foci can be distinguished (arrows). BAC 52E20 produces overall weaker FISH pattern with two chromosome pairs showing relatively strong foci covering most of the chromosomes and about nine others with weak signals (Fig. 4b). The 72C16 and 95J22 BACs produce clear foci on almost all chromosomes, but some chromosomes display much stronger FITC fluorescence (Fig. 4c, d). BAC 17J22 shows more distinct foci on about 15 chromosomes and weak dispersed signals on several others (Fig. 4e).

Table 3 Secondary chromosome associations in 16 pollen mother cells at diakinesis of the KPS 01-01-25 sugarcane

\begin{tabular}{|c|c|c|c|c|c|c|c|c|c|c|c|}
\hline \multirow[b]{2}{*}{ Number of secondary chromosome associations } & \multicolumn{10}{|c|}{ Secondary chromosome associations } & \multirow[t]{2}{*}{ Total } \\
\hline & 3 & 4 & 5 & 6 & 7 & 8 & 9 & 10 & 11 & 12 & \\
\hline Number per cell & 10 & 85 & 8 & 42 & 8 & 18 & 10 & 17 & 12 & 16 & 226 \\
\hline Percentage & 4.42 & 37.61 & 3.54 & 18.58 & 3.54 & 7.96 & 4.42 & 7.52 & 5.31 & 7.08 & 100 \\
\hline
\end{tabular}


Fig. 2 Fluorescent in situ hybridization of $5 \mathrm{~S}$ (red) and $45 \mathrm{~S}$ rDNA probes (green) on a pollen mother cell at diakinesis of the KPS 01-01-25 sugarcane. a The three-color image shows eight foci of the $45 \mathrm{~S}$ rDNA (and one very small spot) and seven signals of the $5 \mathrm{~S}$ rDNA probe, respectively. b Raw image of the red fluorescence of the $5 \mathrm{~S}$ rDNA probe displays four minor fluorescent spots (arrows), few of them composed of double spots (arrowheads)
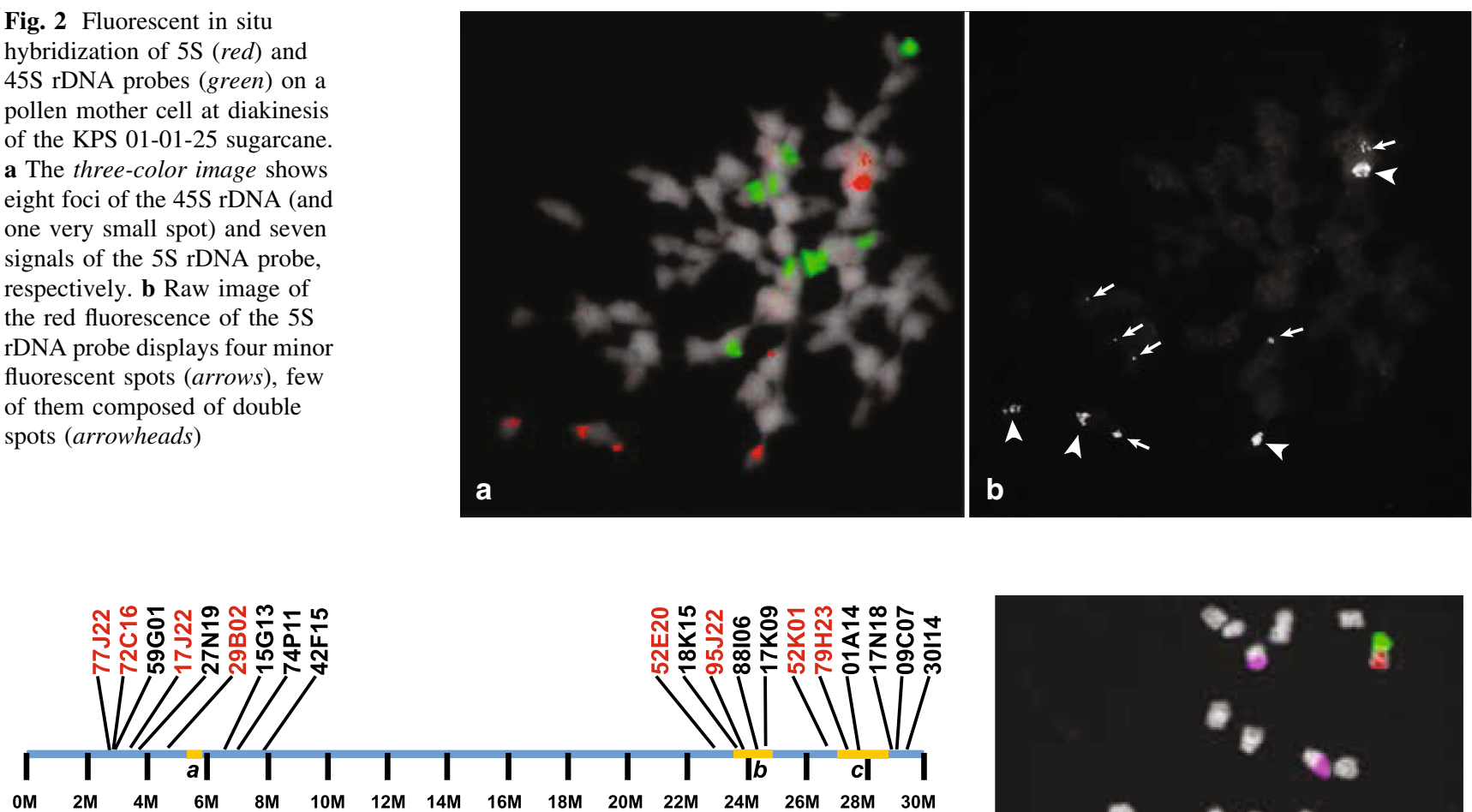

(a)

(c)

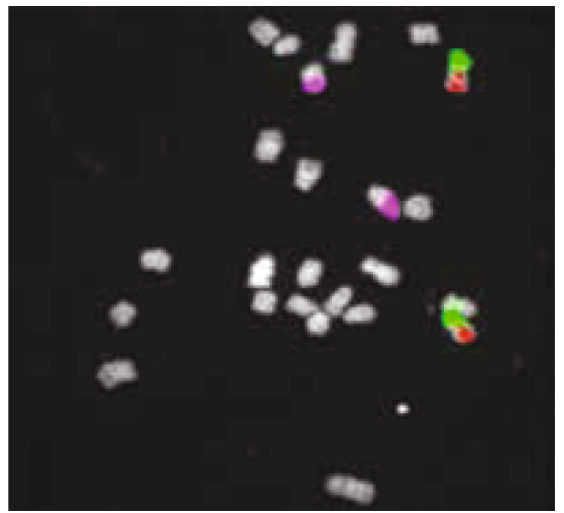

\section{㫄 N}

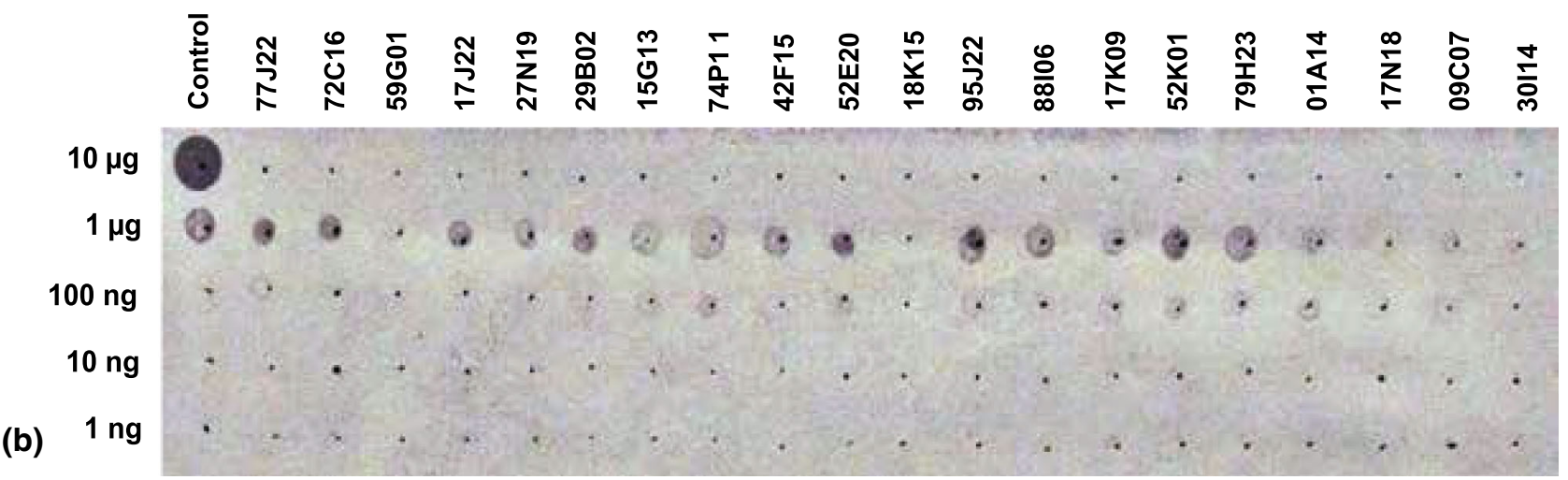

Fig. 3 a Position of the 20 BACs located on rice chromosome 5 that were initially selected for the cross-species FISH experiments. The BACs cover three chromosome regions around drought genes for grain width $(a)$, root trait $(b)$ and grain weight $(c)$, see Table 1 for more information. b Dot-blot hybridization of the same 20 BACs. The rice BACs with relatively strongest hybridization signals on the dot blot (77J22, 72C16, 17J22, 29B02, 52E20, 95J22, 52K01 and 79H23)

BAC 52K01 follows the same pattern but its distribution is more dispersed on some of the chromosomes (Fig. 4f). The BACs 29B02 and 79H23 hybridizes on most of the chromosomes, in the middle of the bivalents and most likely were selected for the cross-species BAC FISH painting experiment. c FISH of the eight selected BACs hybridized on cell complements of Oryza sativa ssp. japonica. The pooled four BACs of the short arm (green fluorescence) and four of the long arm (red fluorescence) showed the position of rice chromosome 5 . The purple fluorescence denotes the two $45 \mathrm{~S}$ rDNA sites of chromosome 2. Bar $5 \mu \mathrm{m}$

around the chiasmata. BAC $29 \mathrm{~B} 02$ paints almost all chromosomes, whereas the BAC $79 \mathrm{H} 23$ fluorescence is clear on about eight chromosomes whereas other chromosomes have no or only very weak foci (Fig. 4g, h). 
Fig. 4 Examples of crossspecies FISH of rice BACs on diakinesis cell complements of the KPS 01-01-25 sugarcane. The yellow (Cy3) fluorescence in all figures denotes the hybridization of $45 \mathrm{~S}$ rDNA FISH, which was used as an internal control. a FISH experiment with BAC 77J22 (FITC, green) shows 15 chromosomes with clear signals, few of them with strong signals and other chromosomes with single small foci (arrows) or faint dispersed signals. b FISH with BAC 52E20 (Cy5, purple) shows two chromosome pairs with big signals and several others with smaller, faint foci. c BAC $72 \mathrm{C} 16$ give dispersed signal in most of the chromosomes. d BAC 95J22 fluorescence is weak with only stronger signals in two chromosome pairs. e BAC 17J22 gives clear signal on $\sim 15$ chromosomes. The arrows show examples of single foci. $\mathbf{f}$ BAC 52K01 fluorescence signals are weak and lie scattered on most of the chromosomes. $g$ BAC 29B02 hybridizes mostly in the middle of most bivalents.

h BAC $79 \mathrm{H} 23$ hybridizes with nine bivalents. Bar in a equals $5 \mu \mathrm{m}$
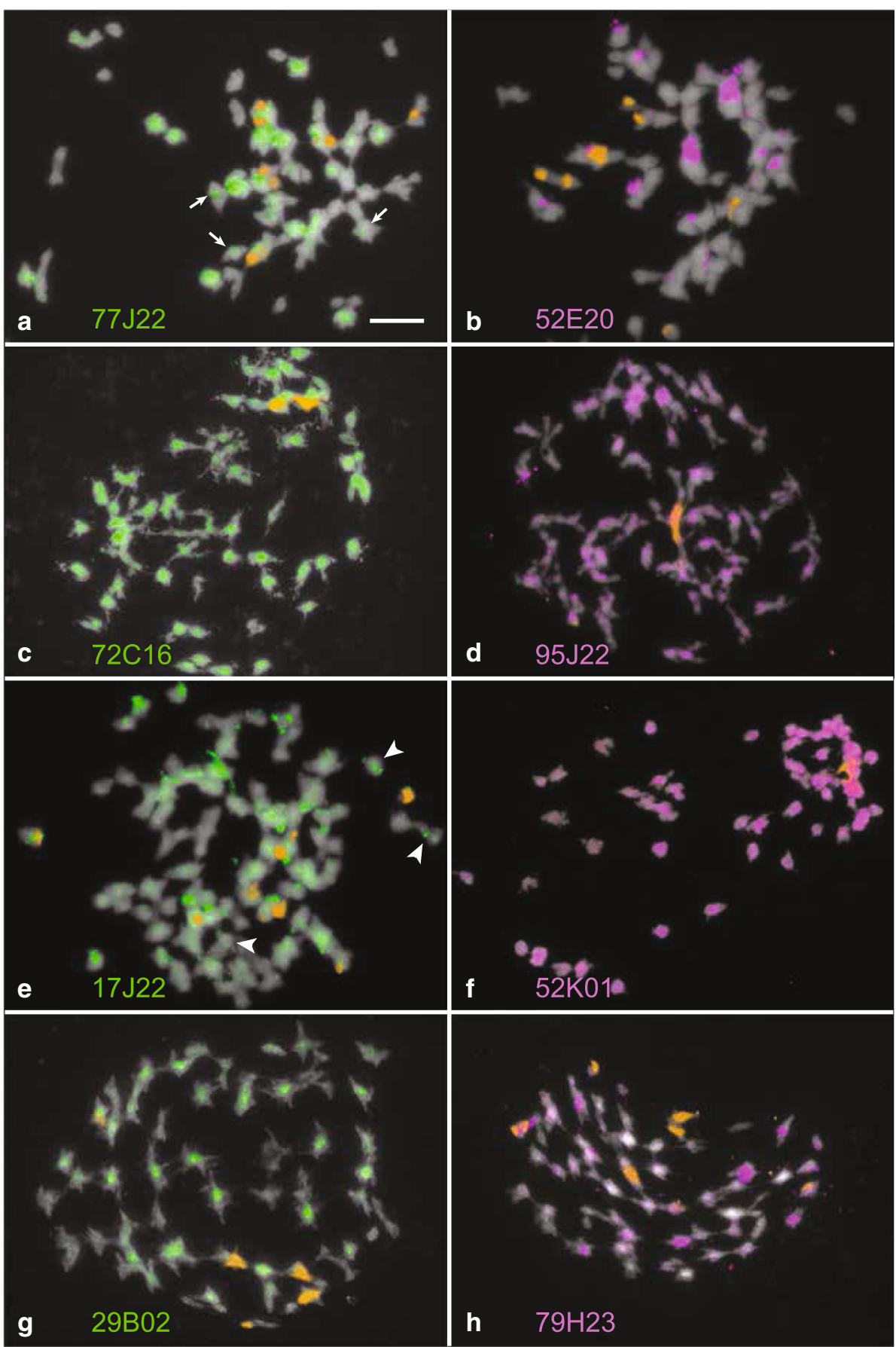

\section{Discussion}

In this study, a cytogenetic characterization of the highly polyploid Thai KPS 01-01-25 sugarcane was presented. For obtaining accurate chromosome counts we analyzed endodiploid tapetal cells as well as cell complements in pollen mother cells at diakinesis and metaphase I. Further insight of the polyploid nature of this variety was obtained by FISH studies with rDNAs and rice BACs as probes. The tapetal cells, which enclose pollen mother cells in young anthers, are highly specialized cells and play an essential role in development and maturation of the microspores by secreting nourishing substances (Maheshwari 1950; Esau 1961). Chromosome preparations of such cells reveal wellspread chromosome complements, even without the use of microtubule arresting drugs like colchicine. Accordingly, we were able to establish that the KPS 01-01-25 sugarcane has 110 chromosomes, a number that is in the range of 80-130 for other modern highly polyploid cultivars (Panje and Babu 1960; Simmonds 1976, 1993; D'Hont et al. 1998; 
Sreenivasan and Jagathesan 1975). Variation in the chromosome numbers can be explained by unequal segregation and restitution of meiotic divisions in the $S$. officinarum $\times$ S. spontaneum hybrids (Bremer 1961; Burner and Legendre 1993; Burner 1997), as well as tolerance for high levels of polyploidy and aneuploidy. Descendants obtained from $S$. officinarum $(2 n=80) \times S$. spontaneum ( $2 n=40-2 n=128)$ crosses were expected to have chromosome numbers between 100 and 144, but never were more than 130 chromosomes observed, probably due to low vigor and quality of the sugarcane at such higher chromosome numbers (Roach 1972). Studies of D'Hont et al. (1996, 1998, 2008), D'Hont and Glaszmann (2001), Piperidis and D'Hont (2001) and Cuadrado et al. (2004) suggest that $70-80 \%$ of the modern sugarcane genome originated from S. officinarum and 20-30\% from $S$. spontaneum, of which about $10 \%$ is composed of homeologous recombinant chromosomes. If we assume that such a genomic composition holds true for the KPS 01-01-25 cultivar, then on average 83 chromosomes are from $S$. officinarum $(x=10)$ and so represent about eight genomes, and 28 chromosomes are from $S$. spontaneum $(x=8)$ and recombinant chromosomes, and so represent 3-4 genomes. Hence the total number of (mono)haploid genomes in this cultivar is estimated at about 11-12.

Further cytogenetic information on this highly polyploid KPS 01-01-25 sugarcane was obtained from analyses of chromosome pairing and chiasma formation in pollen mother cells at meiotic prophase I. Meiocytes at pachytene revealed an inextricable network of chromosomes and bivalents, which could not be traced from end to end. Chromosomes display a pattern of smaller and numerous chromomeres and little or no heterochromatin blocks around the centromeres. Pairing for as far detectable was mostly composed of two chromosomes and there was no indication for triple or quadruple pairing (cf. Wagenvoort 1995; Grandont et al. 2013), but pairing partner switches were clearly detectable (Sherman et al. 1989). Only few pairing partner exchanges could be observed, which might explain the occurrence of some multivalents that we observed in cells at diakinesis and metaphase I. In addition we also observed few small loops that point at inversions, duplications or deletions. Some of such loops may lead to anaphase bridges, which indeed were observed incidentally.

Pollen mother cells at diakinesis demonstrated two types of associations between the chromosomes. We distinguished true chiasma bonds between the homologues/ homeologues and secondary chromosome associations between chromosomes, either as univalents, bivalents or other chiasma configurations. The former connections are found in the tightly shaped bivalents, and the few putative trivalents and quadrivalents found in our material
(Table 2). Bivalents are by far the largest class of chiasma associations reflecting the strong preferential pairing of homologues, which corresponds to previous studies of highly polyploid sugarcane meiosis (Sreenivasan and Jagathesan 1975; Sreenivasan and Sreenivasan 1984; Burner 1991; Burner and Legendre 1993; Al-Janabi et al. 1994; Premachandran et al. 2011; Jannoo et al. 2004; Garsmeur et al. 2011).

The second type of chromosome connections are the secondary chromosome associations, which are DAPI positive diffuse threads that were observed in all anthers with meiocytes at diakinesis/metaphase I (Table 3). The cell complement in Fig. $1 \mathrm{c}$ is the most conspicuous example of secondary associations that we found in our material. Secondary associations were first described by Lawrence (1931) and were thereafter regularly referred to in meiotic studies of several plant species, most of them about polyploid species (Gustafsson 1935; Kempanna and Riley 1964; Kumar and Singhal 2013), including sugarcane (Sreenivasan and Jagathesan 1975). Such associations were also described in haploids (Sadasivaiah and Kasha 1971; Jelenkovic et al. 1980), in material exposed to ionizing radiation and mutagenic treatments (Kumar and Chaudhary 2014) and even in the ancestral polyploid Brassica oleracea (Wills 1966; Ji et al. 2014). Although the nature for such associations may be different in the examples mentioned above, the general clarification for this phenomenon points at residual homology or duplicated segments between homeologous and non-homologous chromosomes as found in (ancestral) polyploids and haploids, respectively (Kempanna and Riley 1964). Klášterská (1976) argued that such threads in multivalent-like associations as found in Rosa meiosis are the result of a disturbed recondensation of the chromosomes after the diffuse diplotene stage and do not reflect any kind of structural hybridity. However, as strong variation in such associations was found between the samples from different seasons it may suggest that environmental conditions play a role in the occurrence of such secondary associations, an explanation that is also favored by Kumar and Chaudhary (2014). Alternatively, Thomas and Revell (1946), and Jelenkovic et al. (1980) suggested that duplications in the heterochromatic segments favors associations between non-homologous parts, which find support in the recent FISH study of Brassica oleracea meiosis (Ji et al. 2014) showing that such inter-bivalent connections contain stretches of $45 \mathrm{~S}$ rDNA and centromere tandem repeats.

We used FISH with the $45 \mathrm{~S}$ and $5 \mathrm{~S}$ rDNA as probes for estimating the degree of polyploidy in the KPS 01-01-25 cultivar. Hybridization revealed eight foci with the $45 \mathrm{~S}$ rDNA probe, and in some nuclei even an additional small spot. FISH using the 5S rDNA probe showed ten signals in a cell complement, of which five are small. Based on the 
110 chromosomes of the sugarcane cultivar and the number of one rDNA per monohaploid genome (Jenkin et al. 1995; D'Hont et al. 1998; Cuadrado et al. 2004) we estimated the number of genomes in this cultivar at 11-12, of which 8-9 genomes are from $S$. officinarum and 3 from $S$. spontaneum or recombinant chromosomes. So in fact, there is a slight discrepancy between the observed rDNA sites and the estimate numbers of genomes. Changes of ribosomal sites were previously documented in interspecific hybrids and referred to as amphiplasty, i.e., morphological changes in chromosomes following interspecific hybridization (Lacadena et al. 1984). These changes in the nucleolar activity as demonstrated by silver nitrate staining in wheat-rye hybrids visualize dynamics of rDNA transcription patterns. This phenomenon is now known as nucleolar dominance and finds its origin in an epigenetic mechanism regulating the paternal discrimination of the chromatin and in particular the rDNA transcription (Pikaard 2000; McStay 2006; Chen 2007; Li and Ge 2007; Ge et al. 2013). Nucleolar dominance is well documented in inter-crossed hybrids and allopolyploids (Kobayashi 2008; Ge et al. 2013) as shown in Brassica allohexaploids (AABBCC), where nucleolar dominance follows a hierarchical order of the parental species involved (Ge et al. 2009). In general this phenomenon is explained as selective 'switching off' of the rDNA activity within the loci that are originated from one ancestral genome, while the activity of the loci from other genome(s) is retained (which is obvious since each cell needs a certain amount of rRNAs to be able to build up new ribosomes and therefore handle its entre metabolism). The lower than expected number of rDNA loci (and-as we can assume-physical reduction or even total elimination of some of them) can be caused by various, most likely 'structural' factors but probably none of them can be linked with predominantly epigenetic phenomenon of nucleolar dominance. As the expression status of $45 \mathrm{~S}$ rDNA loci in this material has not been determined by silver staining combined with FISH with $45 \mathrm{~S} / 25 \mathrm{~S}$ rDNA probe, there is not much to say about the activity of this class of rRNA genes within particular loci. To authoritatively say if there is (or not) any nucleolar dominance in this material, it would most likely require even more complex studies, such as molecular analysis of the organization in these rRNA genes.

The cross-species FISH experiments were included to explore the possibility of mapping DNA chromosome regions on the cell complement of sugarcane that are (partly) homologous with three regions on rice chromosome 5 containing economically important drought genes. The feasibility of such experiments was inspired by successful examples of recent chromosome painting in higher plants, especially from painting the chromosome complements of Arabidopsis and distant species and crops of the
Brassicaceae using chromosome-specific Arabidopsis BAC contigs (Lysak et al. 2003; Lysak and Koch (2011). Crossspecies BAC FISH painting was also demonstrated in tomato and potato Tang et al. (2008), and was later extended to a phylogenetic chromosome study of other Solanum and Capsicum crops (Iovene et al. 2008; Szinay et al. (2012). In the grass family, the first large-scale comparative chromosome painting (CCP) was performed with chromosomespecific BAC probes from Brachypodium distachyon to homoeologous chromosomes of its close relatives (Idziak et al. 2014; Betekhtin et al. 2014). In our comparative chromosome painting experiments of rice BACs on sugarcane chromosome complements we expected distinct fluorescent foci on the sugarcane cell complement that roughly correspond to the number of genomes, in this case 11 or 12 (apart from eventual recombinant chromosomes). The grounds on which rice BACs were chosen as probe DNA was the public availability of extensive genomic information and BAC libraries of this model species on the moment we started the experiments. We also argued that the transcriptome sequences of rice and sugarcane would correspond sufficiently to make a cross-species FISH possible, while repetitive sequences of rice would not interfere with the hybridization producing multiple foci on the chromosomes produced by LTR retrotransposons, LINEs and SINEs, and other dispersed repetitive elements. However, the two groups of rice chromosome 5 BACs containing drought resistance genes and a relatively higher homology with sugarcane (Fig. 3) displayed different fluorescent patterns on the sugarcane chromosomes. BAC $17 \mathrm{~J} 22$ (Fig. 4e) and to a less extent, BAC 77J22 and 52E20 (Fig. 4a, b) display distinct fluorescent foci, 9-10 of them pretty small and visible on both hom(e)ologues of the bivalent. The FISH signals cover only part of the chromosomes and vary from large dispersed patterns to single small foci. BAC 77J22 (Fig. 4a) produces strong signals on about $2 / 3$ of all chromosomes pointing at repetitive sequences that are present in several chromosomes. The fluorescence patterns of the BACs 29B02 and 79H23 (Fig. 4g, h) paint about $3 / 4$ of the chromosomes, but fluorescence is stronger in the middle of the bivalents, which we consider the regions around the chiasmata, and supposedly the euchromatic parts of the chromosomes. It is obvious that most of the fluorescence spots and dispersed signal are hybridizations of the repetitive DNA, like LTR retrotransposons. It is not known though, why several of the BACs paint only part of the chromosomes; this may be due to differentiation of $S$. officinarum and S. spontaneum genomic repeats. Support for differences comes from the genomic painting (genomic in situ hybridization) experiments of D'Hont (2005) demonstrating total genomic DNA differentiation of modern sugarcane cultivars with probes of the two parental species. 
It is clear that this chromosome painting of rice BACs on sugarcane chromosomes is a pilot study, and should be considered as a new step in sugarcane cytogenetics. Although BAC libraries of sugarcane are available (Tomkins et al. 1999; Figueira et al. 2012) new attempts are needed for chromosome mapping using pooled seed BACs anchored with genetic markers on the sugarcane linkage maps (Ferrari et al. 2009). Alternatively, cross-species BAC FISH painting can be further explored using sorghum DNA as probes, which may be a better choice for painting sugarcane chromosomes considering the micro-collinearity (Ilic et al. 2003) between the two crop species (Jannoo et al. 2007). To date, Aitken et al. (2014) confirmed that sorghum is phylogenetically more related to sugarcane than any other grass crop.

Acknowledgments The authors are thankful to Wageningen University, Laboratory of Genetics, The Netherlands and Higher Education Research Promotion and National Research University Project of Thailand, Office of the Higher Education Commission for providing necessary funds and facilities. The equipment and technical support were kindly provided by José Van de Belt, Dóra Szinay, Bertha Koopmans, Xianwen Ji from the Wageningen Lab. Rewat Lersrutaiyotin from the Cane and Sugar Research and Development Center of Kasetsart University was helpful with collecting the sugarcane flower bud material.

\section{Compliance with ethical standards}

Conflict of interest The authors declare that they have no conflict of interest.

Open Access This article is distributed under the terms of the Creative Commons Attribution 4.0 International License (http://creative commons.org/licenses/by/4.0/), which permits unrestricted use, distribution, and reproduction in any medium, provided you give appropriate credit to the original author(s) and the source, provide a link to the Creative Commons license, and indicate if changes were made.

\section{References}

Aitken KS, McNeil MD, Berkman PJ, Hermann S, Kilian A, Bundock PC, Li J (2014) Comparative mapping in the Poaceae family reveals translocations in the complex polyploidy genome of sugarcane. BMC Pl Biol 14:190

Al-Janabi SM, Honeycutt RJ, Sobral BWS (1994) Chromosome assortment in Saccharum. Theor Appl Genet 89:959-963. doi:10.1007/BF00224524

Betekhtin A, Jenkins G, Hasterok R (2014) Reconstructing the evolution of Brachypodium genomes using comparative chromosome painting. PLoS ONE 9:e115108. doi:10.1371/journal. pone. 0115108

Bremer G (1961) Problems in breeding and cytology of sugar cane. Euphytica 10:59-78. doi:10.1007/BF00037206

Burner DM (1991) Cytogenetic analyses of sugarcane relatives (Andropogoneae: Saccharinae). Euphytica 54:125-133. doi:10. 1007/BF00145639

Burner DM (1997) Chromosome transmission and meiotic behavior in various sugarcane crosses. J Amer Soc Sugar Cane Technol $17: 38-50$
Burner DM, Legendre BL (1993) Chromosome transmission and meiotic stability of sugarcane (Saccharum spp.) hybrid derivatives. Crop Sci 33:600-606

Chen ZJ (2007) Genetic and epigenetic mechanisms for gene expression and phenotypic variation in plant polyploids. Annual Rev Pl Biol 58:377-406

Chen M, Presting G, Bradbazuk WB, Goicoechea JL, Blackmon B et al (2002) An integrated physical and genetic map of the rice genome. Pl Cell 14:537-545

Cheng CH, Chung MC, Liu SM, Chen SK, Kao FY, Lin SJ, Hsiao SH, Tseng IC, Hsing YIC, Wu HP, Chen CS, Shaw JF, Wu J, Matsumoto T, Sasaki T, Chen HH, Chow TY (2005) A fine physical map of the rice chromosome 5. Molec Genet Genomics 274:337-345

Cuadrado and Jouve (1995) Fluorescent in situ hybridization and C-banding analyses of highly repetitive DNA sequences in the heterochromatin of rye (Secale montanum Guss.) and wheat incorporating $S$. montanum chromosome segments. Genome 38:796-802

Cuadrado A, Acevedo R, de la Espina SMD, Jouve N, de la Torre C (2004) Genome remodeling in three modern $S$. officinarum $\times S$. spontaneum sugarcane cultivars. J Exp Bot 55:847-854

D'Hont A, Glaszmann JC (2001) Sugarcane genome analysis with molecular markers, a first decade of research. Proc Int Soc Sugar Cane Technol 24:556-559

D'Hont A, Grivet L, Feldmann P, Rao S, Berding N, Glaszmann JC (1996) Characterisation of the double genome structure of modern sugarcane cultivars (Saccharum spp.) by molecular cytogenetics. Molec Gen Genet 250:405-413

D'Hont A, Ison D, Alix K, Roux C, Glaszmann JC (1998) Determination of basic chromosome numbers in the genus Saccharum by physical mapping of ribosomal RNA genes. Genome 41:221-225

D'Hont A, Paget-Goy A, Escoute J, Carreel F (2000) The interspecific genome structure of cultivated banana, Musa spp. revealed by genomic DNA in situ hybridization. Theor Appl Genet 100:177-183

D'Hont A (2005) Unraveling the genome structure of polyploids using FISH and GISH; examples of sugarcane and banana. Cytogenet Genome Res 109:27-33

D'Hont A, Souza GM, Menossi M et al (2008) Sugarcane: a major source of sweetness, alcohol, and bio-energy. In: Moore PH, Ming R (eds) Genomics of tropical crop plants. Springer, Berlin, pp 483-513

Esau K (1961) Anatomy of seed plants. Wiley, New York

Ferrari F, Zanca AS, Jordão H, Giachetto PF, Okura VK, Maccheroni W, Forni-Martins ER (2009) Sugarcane BAC selection for BACFISH in currents hybrids varieties. In: Resumos do $55^{\circ}$ Congresso Brasileiro de Genética. Águas de Lindóia, SP, Brasil

Figueira TRS, Okura V, da Silva FR, da Silva MJ, Kudrna D, Ammiraju JSS, Talag J, Wing R, Arruda P (2012) A BAC library of the SP30-3280 sugarcane variety (Saccharum sp.) and its inferred microsynteny with the sorghum genome. BMC Res Notes 5:185

Figueroa DM, Bass HW (2010) A historical and modern perspective on plant cytogenetics. Brief Funct Genomics 9:95-102

Fransz PF, Alonso-Blanco C, Liharska TB, Peeters AJM, Zabel P, de Jong JH (1996) High resolution physical mapping in Arabidopsis thaliana and tomato by fluorescence in situ hybridization to extended DNA fibres. Plant J 9:421-430

Garsmeur O, Charron C, Bocs S, Jouffe V, Samain S et al (2011) High homologous gene conservation despite extreme autopolyploid redundancy in sugarcane. New Phytol 189:629-642

Ge XH, Wang J, Li ZY (2009) Different genome-specific chromosome stabilities in synthetic Brassica allopolyploids revealed by wide cross with Orychophragms. Ann Bot (Oxford) 104:19-31 
Ge XH, Ding L, Li YZ (2013) Nucleolar dominance and different genome behaviors in hybrids and allopolyploids. Pl Cell Rep 32:1661-1673

Gerlach WL, Bedbrook JR (1979) Cloning and characterization of ribosomal RNA genes from wheat and barley. Nucleic Acids Res 7:1869-1885

Gerlach WL, Dyer TA (1980) Sequence organization of the repeated units in the nucleus of wheat which contains 5S-rDNA genes. Nucleic Acids Res 8:4851-4865

Grandont L, Jenczewski E, Lloyd A (2013) Meiosis and its deviations in polyploid plants. Cytogenet Genome Res 140:171-184. doi:10.1159/000351730

Gustafsson $\AA$ (1935) primary and secondary association in Taraxacum. Hereditas 20:1-31. doi:10.1111/j.1601-5223.1935.tb03176.x

Ha S, Moore P, Heinz D, Kato S, Ohmido N, Fukui K (1999) Quantitative chromosome map of the polyploid Saccharum Spontaneum by multicolor fluorescence in situ hybridization and imaging methods. Pl Molec Biol 39:1165-1173

Hodkinson TR, Chase MW, Lledó MD, Salamin N, Renvoize A (2002) Phylogenetics of Miscanthus, Saccharum and related genera (Saccharinae, Andropogoneae, Poaceae) based on DNA sequences from ITS nuclear ribosomal DNA and plastid trnL intron and $t r n L-F$ intergenic spacers. J Pl Res 115:381-392

Idziak D, Hazuka I, Poliwczak B et al (2014) Insight into the karyotype evolution of Brachypodium species using comparative chromosome barcoding. PLoS ONE 9:e93503. doi:10.1371/ journal.pone.0093503

Ilic K, SanMiguel JP, Bennetzen JL (2003) A complex history of rearrangement in an orthologous region of the maize, sorghum, and rice genomes. Proc Natl Acad Sci USA 100:12265-12270

Iovene M, Wielgus SM, Simon PW et al (2008) Chromatin structure and physical mapping of chromosome 6 of potato and comparative analyses with tomato. Genetics 180:1307-1317. doi:10. 1534/genetics.108.093179

Jacobsen E, de Jong JH, Kamstra SA, van den Berg PMMM, Ramanna MS (1995) Genomic in situ hybridization (GISH) and RFLP analysis for the identification of alien chromosomes in the backcross progeny of potato $(+)$ tomato fusion hybrids. Heredity $74: 250-257$

Jannoo N, Grivet L, David J, D'Hont A, Glaszmann JC (2004) Differential chromosome pairing affinities at meiosis in polyploid sugarcane revealed by molecular markers. Heredity 93:460-467. doi:10.1038/sj.hdy.6800524

Jannoo N, Grivet L, Chantret N, Garsmeur O, Glaszmann JC et al (2007) Orthologous comparison in a gene-rich region among grasses reveals stability in the sugarcane polyploid genome. Plant J 50:574-585

Jelenkovic G, Shifriss O, Harrington E (1980) Association and distribution of meiotic chromosomes in a haploid of Ricinus communis L. Cytologia 45:571-577. doi:10.1508/cytologia.45.571

Jenkin MJ, Reader SM, Purdie KA, Miller TE (1995) Detection of rDNA sites in sugarcane by FISH. Chromosome Res 3:444-445

Ji X, Sharifzadeh-Dehkordi L, Lelivelt C, de Jong H, Wijnker E (2014) Meiotic aberrations leading to aneuploidy in cauliflower (Brassica oleracea L. var. botrytis). In: Ji X, Numerical and structural chromosome aberrations in cauliflower (Brassica oleracea var. botrytis) and Arabidopsis thaliana. PhD Thesis, Wageningen University, Wageningen. ISBN 978-94-6257-160-0

Kempanna C, Riley R (1964) Secondary association between genetically equivalent bivalents. Heredity (Edinb) 19:289-299

Khowaja SF, Norton GJ, Courtois B, Price AH (2009) Improved resolution in the position of drought-related QTLs in a single mapping population of rice by meta-analysis. BMC Genom 10:276. doi:10.1186/1471-2164-10-276
Kim JS, Childs KL, Islam-Faridi MN, Menz MA, Klein RR, Klein PE et al (2002) Integrated karyotyping of sorghum by in situ hybridization of landed BACs. Genome 45:402-412

Kim C, Lee TH, Comptom RO, Robertson JS, Pierce GJ, Paterson AH (2013) A genome-wide BAC end-sequence survey of sugarcane elucidates genome composition, and identifies BACs covering much of the euchromatin. Pl Molec Biol 81:139-147

Klášterksá (1976) A new look on the role of the diffuse stage in cytological problems of plant and animal meiosis. Hereditas 82:193-204

Kobayashi T (2008) A new role of the rDNA and nucleolus in the nucleus-rDNA instability maintains genome integrity. Bioessays 30:267-272

Kumar G, Chaudhary N (2014) Secondary chromosomal association in kidney bean (Phaseolus vulgaris L.). Jordan J Biol Sci 7:71-77

Kumar P, Singhal VK (2013) Chromosome number and secondary chromosomal associations in wild populations of Geranium pratense L. from the cold deserts of Lahaul-Spiti (India). Cytol Genet 47:107-114. doi:10.3103/S0095452713020084

Lacadena JR, Cermeno MC, Orellana J, Santos JL (1984) Evidence for wheat-rye nucleolar competition (amphiplasty) in triticale by silver-staining procedure. Theor Appl Genet 67:207-213

Lawrence WJC (1931) The secondary association of chromosomes. Cytologia 2:352-384. doi:10.1508/cytologia.2.352

Li ZY, Ge XH (2007) Unique chromosome behavior and genetic control in Brassica $\times$ Orychophragmus wide hybrids: a review. Pl Cell Rep 26:701-710

Lim KB, Ramanna MS, de Jong JH, Jacobsen E, Van Tuyl JM (2001) Indeterminate meiotic restitution (IMR): a novel type of meiotic nuclear restitution mechanism detected in interspecific lily hybrid by GISH. Theor Appl Genet 113:219-230

Lysak MA, Koch MA (2011) Phylogeny, genome, and karyotype evolution of crucifers (Brassicaceae). In: Schmidt R, Bancroft I (eds) Genetics and genomics of the Brassicaceae. Springer, Berlin, pp 1-31. doi:10.1007/978-1-4419-7118-0_1

Lysak MA, Pecinka A, Schubert I (2003) Recent progress in chromosome painting of Arabidopsis and related species. Chromosome Res 11:195-204

Maheshwari P (1950) An introduction to the embryology of angiosperms. McGraw-Hill Book Company, New York

McStay (2006) Nucleolar dominance: a model for rRNA gene silencing. Genes Dev 20:1207-1214

Panje R, Babu (1960) Studies in Saccharum spontaneum. Distribution and geographical association of chromosome numbers. Cytologia (Tokyo) 25:152-172

Pikaard CS (2000) Nucleolar dominance: uniparental gene silencing on a multi-megabase scale in genetic hybrids. Pl Molec Biol 43:163-177

Piperidis A, D'Hont A (2001) Chromosome composition analysis of various Saccharum interspecific hybrids by genomic in situ hybridisation (GISH). Proc Int Soc Sugar Cane Technol 24:556-559

Premachandran MN, Prathima PT, Lekshmi M (2011) Sugarcane and polyploidy-a review. J Sugarcane Res 1:1-15

Roach BT (1972) Nobilisation of sugarcane. Proc Int Soc Sugar Cane Technol 14:206-216

Sadasivaiah RS, Kasha KJ (1971) Meiosis in haploid barley-an interpretation of non-homologous chromosome associations. Chromosoma 35:247-263. doi:10.1007/BF00326277

Sasaki T, Burr B (2000) International rice genome sequencing project: the effort to completely sequence the rice genome. Curr Opin Pl Biol 3:138-141

Sherman JD, Stack SM, Anderson LK (1989) Two-dimensional spreads of synaptonemal complexes from solanaceous plants. IV. 
Synaptic irregularities. Genome 32:743-753. doi:10.1139/g89507

Simmonds NW (1976) Sugarcanes. In: Simmonds NW (ed) Evolution of Crop plants. Longmans, England, pp 104-108

Simmonds NW (1993) Introgression and incorporation. Strategies for the use of crop genetic resources. Biol Rev Camb Philos Soc 68:539-562. doi:10.1111/j.1469-185X.1993.tb01243.x/-abstract

Sreenivasan TV, Jagathesan D (1975) Meiotic abnormalities in Saccharum spontaneum. Euphytica 24:543-549

Sreenivasan TV, Sreenivasan J (1984) Cytology of saccharum complex from new Guinea, Indonesia and India. Karyologia 37:351-357. doi:10.1080/00087114.1984.10797713

Szinay D, Wijnker E, van den Berg R et al (2012) Chromosome evolution in Solanum traced by cross-species BAC-FISH. New Phytol 195:688-698. doi:10.1111/j.1469-8137.2012.04195.x

Tang X, Szinay D, Lang C et al (2008) Cross-species bacterial artificial chromosome-fluorescence in situ hybridization painting of the tomato and potato chromosome 6 reveals undescribed chromosomal rearrangements. Genetics 180:1319-1328. doi:10. 1534/genetics.108.093211

Thomas PT, Revell SH (1946) Secondary association and heterochromatic attraction. I. Cicer arietinum. Ann Bot (Oxford) 10:159-164

Tomkins JP, Yu Y, Miller-Smith H, Frisch DA, Woo SS, Wing RA (1999) A bacterial artificial chromosome library for sugarcane. Theor Appl Genet 99:419-424

Vega JM, Shahal Abbo, Feldman M, Levy AA (1994) Chromosome painting in plants: in situ hybridization with DNA probe from a specific microdissected chromosome arm of common wheat. Proc Natl Acad Sci USA 91:12041-12045

Wagenvoort M (1995) Meiotic behaviour of 11 primary trisomics in diploid potato and its consequences for the transmission of the extra chromosome. Genome 38:17-26. doi:10.1139/g95-003

Wan X, Weng J, Zhai H, Wang J, Lei C et al (2008) Quantitive trait loci (QTL) analysis for rice grain width and fine mapping of identified QTL allele $g w-5$ in a recombination hotspot region on chromosome 5. Genetics 179:2239-2252

Wang GL, Holsten TE, Song WY, Wang HP, Ronald PC (1995) Construction of rice bacterial artificial chromosome library and identification of clones linked to the Xa-21 disease-resistance locus. Plant J 7:525-533

Wang GL, Warren R, Innes R, Osborne B, Baker B, Ronald PC (1996) Construction of an Arabidopsis BAC library and isolation of clones hybridizing with disease-resistance, gene-like sequences. Pl Molec Biol Rep 14:107-114

Wills AB (1966) Meiotic behaviour in the Brassiceae. Caryologia 19:103-116. doi:10.1080/00087114.1966.10796209

Woo SS, Jiang JM, Gill BS, Paterson AP, Wing RA (1994) Construction and characterization of a bacterial artificial chromosome library of sorghum bicolor. Nucleic Acids Res 22:4922-4931

Yoshida S, Ikegami M, Kuze J, Sawada K, Hashimoto Z et al (2002) QTL analysis for plant and grain characters of Sake-brewing rice using a doubled haploid population. Breeding Sci 52:309-317

Zwick MS, Hanson RE, McKnight TD, Islam-Faridi MH, Stelly DM, Wing RA, Price HJ (1997) A rapid procedure for the isolation $C_{0} t-1$ DNA from plants. Genome 40:138-142 